\title{
Human Bronchus and Intestine Express the Same Mucin Gene
}

\author{
Berthold H. Jany, *' Marianne W. Gallup,*" Pei-Sha Yan," James R. Gum," Young S. Kim,"*l and Carol B. Basbaum*\$ \\ ${ }^{*}$ Departments of Anatomy, ${ }^{\ddagger}$ Medicine, and ${ }^{8}$ Cardiovascular Research Institute, University of California San Francisco, and \\ "Gastrointestinal Research Laboratory, Veterans Administration Hospital San Francisco, San Francisco, California 94143
}

\begin{abstract}
The amino acid and sugar composition of mucins from various organs is similar but not identical. This could arise by one or more of the following: organ-specific processing of a single core protein, organ-specific splicing of a single mucin mRNA, or organ-specific expression of various mucin genes. To begin to investigate the source of this variability, we examined $(a)$ immunological cross-reactivity and (b) cDNA cross-hybridization, among several mucin-secreting organs of the human body. Peptide-directed antibodies raised against both nondeglycosylated (LS) and deglycosylated (HFB) intestinal mucin strongly stained mucous cells in the bronchial epithelium and submucosal glands, indicating homology between mucins of the bronchus and intestine at the peptide level. By screening a bronchus cDNA library with an intestinal mucin CDNA, SMUC-41, we isolated a bronchus mucin cDNA, HAM-1. This cDNA is $96 \%$ homologous to the first repeat of SMUC-41. HAM-1 hybridized to restriction fragments of human genomic DNA identical to those hybridizing to SMUC-41 on Southern blots. SMUC41 also hybridized to polydisperse transcripts in the bronchus, cervix, gall bladder, and mammary gland, indicating mucin homology among all these organs at the RNA level. We conclude that the bronchus and intestine express a common mucin gene, which is likely co-expressed by at least several other mucin-secreting organs. (J. Clin. Invest. 1991. 87:77-82.) Key words: mucus hypersecretion - mammary mucin - gall bladder mucin • cervical mucin • cystic fibrosis
\end{abstract}

\section{Introduction}

Mucin is a high-molecular weight glycoprotein that plays important roles at several mucosal surfaces of the body including respiratory (1), gastrointestinal (2), and urogenital (3) tracts. Biochemical analysis of purified mucins from various human tissues shows that they share several general properties: high molecular weight $\left(>10^{6} \mathrm{D}\right)$, high carbohydrate content $(70$ $80 \%$ ), and oligosaccharides consisting of $N$-acetyl galactosamine, galactose, fucose, sialic acid, and $N$-acetyl glucosamine (4). The latter are joined by $O$-glycosidic linkages to the core protein or apomucin, which is typically rich in hydroxyamino

A preliminary report appeared in abstract form (1989. Eur. Respir. J. 2:280s [Abstr.]). Sequence data is being submitted to Genbank.

Address reprint requests to Carol B. Basbaum, Ph.D., Department of Anatomy and Cardiovascular Research Institute, University of California San Francisco, San Francisco, CA 94143. 1990.

Received for publication 1 May 1990 and in revised form 20 August

J. Clin. Invest.

(c) The American Society for Clinical Investigation, Inc.

$0021-9738 / 91 / 01 / 0077 / 06 \$ 2.00$

Volume 87, January 1991, 77-82 acids (2, 5-7). However, despite these similarities, extensive microheterogeneity exists, with mucins from various sources showing different stoichiometry of amino acids and sugars (compare 5, 7-9).

The significance of the biochemical differences between mucins has remained obscure. One possibility is that different mucin genes are expressed in different organs to serve organspecific functions. Thus, mucin of the respiratory tract, whose principal role is in mucociliary clearance (1), differs chemically from mucin in the cervix, whose principal role is in fertilization (10). It has been disputed as to whether these diverse functions could be served by a single mucin gene.

Recently, apomucin cDNAs have been cloned from human mammary tumor (11) and intestine (12). Although full-length cDNAs have not yet been reported, nucleotide and amino acid comparison indicates no similarities, except for the presence of tandem repeats of different lengths. Chromosome mapping shows the two genes are located on different chromosomes, supporting a one-organ-one-gene hypothesis. On the other hand, a comparison of amino acid composition between airway and intestinal mucins $(2,7,8)$ revealed a high degree of similarity. Furthermore, recent data showed that antibodies raised against the core protein of bronchial mucin cross-reacted with mucin in intestinal goblet cells, strengthening the possibility of close structural homology between mucins from the two organs (13). On this basis, it seemed possible that the airways and the intestinal tract might express a single, or two closely related, mucin genes.

Using an intestinal mucin cDNA, SMUC 41 (12), we have shown that the same mucin gene is not only expressed in the airways and intestine, but is homologous to a gene or genes expressed in the gallbladder, cervix, and mammary gland. Using this cDNA, we have isolated a mucin cDNA from human bronchus whose properties confirm its relationship to the SMUC-41 gene. This cDNA should prove useful in studies of the regulation of mucin gene expression in disorders such as cystic fibrosis (14), chronic bronchitis (15-17), and bronchial carcinoma (17-21).

\section{Methods}

Histology and immunocytochemistry. Antibodies used in this study were described previously $(12,22)$. Briefly, mucin was purified from nude mouse xenografts of LS174T human colon carcinoma cells and deglycosylated using anhydrous hydrogen fluoride. Rabbit polyclonal antibodies were raised by using untreated mucin (LS), partially deglycosylated product predominantly consisting of GalNac-apomucin (HFA), and totally deglycosylated mucin (HFB) as immunogens.

Paraffin sections $(5 \mu \mathrm{m})$ of surgical specimens of human bronchial tissue were deparaffinized before routine staining with hematoxylin and eosin or prepared for immunocytochemistry. For immunocytochemistry, sections were rinsed in PBS and then blocked in 5\% normal rabbit serum in PBS. All reactions were carried out at room temperature. Antibodies were diluted in PBS. Antibody was applied to sections for $2 \mathrm{~h}$. After rinsing, sections were incubated with second antibody 
consisting of goat anti-rabbit IgG-biotin. After rinsing, sections were incubated with streptavidin-peroxidase conjugate, and rinsed again before development of the reaction with diaminobenzidine. Sections were counterstained with methyl green, covered with Permount, and photographed using a Zeiss photomicroscope.

RNA blots. Total RNA was extracted from human airways and other human tissues as described (23). Poly $\mathrm{A}^{+}$RNA was selected using oligo- $d T$-cellulose (Collaborative Research, Inc., Waltham, MA) column chromatography. RNA was fractionated by denaturing $1 \%$ agarose/formaldehyde gel electrophoresis and transferred to a nylon membrane (GeneScreen, New England Nuclear, Boston, MA) by capillary blotting. cDNA probes were labeled with $\left[{ }^{32} \mathrm{P}\right] \mathrm{dCTP}$ (Amersham Corp., Arlington Heights, IL) by the random priming method (BRL Random Priming Kit) to a specific activity of $>10^{9} \mathrm{cpm} / \mu \mathrm{g}$ DNA. Hybridization was performed at $42^{\circ} \mathrm{C}$ for $16-24 \mathrm{~h}$ in a solution containing $50 \%$ formamide, $1.0 \mathrm{M} \mathrm{NaCl}, 0.2 \% \mathrm{BSA}, 0.2 \%$ Ficoll, $0.05 \mathrm{M}$ Tris- $\mathrm{HCl}(\mathrm{pH} 7.0), 0.1 \%$ sodium pyrophosphate, $10 \%$ dextran sulfate, and denatured salmon sperm DNA $(>100 \mu \mathrm{g} / \mathrm{ml})$. Blots were then washed in $0.3 \mathrm{M} \mathrm{NaCl}, 0.03 \mathrm{M} \mathrm{Na}$-citrate $(2 \times \mathrm{SSC})$ at room temperature, $0.2 \times \mathrm{SSC}, 1 \% \mathrm{SDS}$ at $63^{\circ} \mathrm{C}$ for $30 \mathrm{~min}$, and $0.2 \times \mathrm{SSC}$ at room temperature for $10 \mathrm{~min}$. After autoradiography, probes were stripped and blots rehybridized with a cDNA probe encoding beta-actin.

Genomic DNA blots. Genomic DNA was prepared from human fibroblasts (24). $10 \mu \mathrm{g}$ DNA was digested to completion with Hind III and Apa I (BRL) as judged by ethidium bromide staining. After electrophoresis through a $0.7 \%$ agarose gel, DNA was transferred to a nylon membrane (GeneScreen, New England Nuclear) by capillary blotting. Hybridization and washing were performed under conditions described above with a modification of hybridization conditions for the smaller probe (no formamide, $60^{\circ} \mathrm{C}$ ).

Construction and screening of a bronchus cDNA library. RNA was extracted as described above from a surgical specimen from a patient with chronic bronchitis. Polyadenylated RNA was enriched by oligo$d T$ column chromatography (Pharmacia Fine Chemicals, Inc., Piscataway, NJ). mRNA was tested by in vitro translation (rabbit reticulocyte lysate, Amersham Corp.). $5 \mu \mathrm{g}$ of poly- $\mathrm{A}^{+} \mathrm{RNA}$ were used for synthesis of oligo- $d T$-primed cDNA, using Amersham's cDNA Synthesis System Plus. Double-stranded cDNA was cloned into the EcoRI site of lambda ZAP II (Stratagene, La Jolla, CA) using Gigapack Gold as a packaging kit (Stratagene). Screening of the library was performed at 3,000 pfu/ $150-\mathrm{mm}$ plate. Plaque lifting to duplicate nitrocellulose filters (Schleicher \& Schuell, Keene, NH) was carried out as described (25). Hybridization, washing, and autoradiography were performed essentially as described above, except that $5 \times \mathrm{SSC}$ was used in the hybridization solution.

Sequencing. Bluescript vector containing the insert of interest was prepared by in vivo excision (26). Nucleotide sequence of both strands was determined by the dideoxy chain termination method (27) using ${ }^{35}$ S]dATP (Amersham Corp.) and modified T7 DNA polymerase (United States Biochemical Corp., Cleveland, $\mathrm{OH}$ ).

\section{Results}

The LS antibody raised against nondeglycosylated intestinal adenocarcinoma mucin stained mature secretory granules in goblet cells of the bronchial epithelium (data not shown) in a similar fashion to that reported for intestinal goblet cells (21). LS antibody also recognized secretory granules in cells of the submucosal glands. Some gland tubules were negative, presumably representing serous gland cells, and possibly including some mucous cells. The HFA antibody, raised against partially deglycosylated mucin, stained mucous gland, and goblet cells below and around the mucous granules (Fig. $1 \mathrm{D}$ ), probably targeting the Golgi apparatus. Using the HFB antibody, raised against totally deglycosylated mucin core protein, reactive areas were below and around the mucous granules, probably targeting both the rough endoplasmic reticulum and Golgi appara- tus (Fig. $1 B$ ). These data provide evidence that mucin core proteins structurally related to those in the intestine are expressed in the bronchus. Although goblet cells and mucous gland cells reacted with the three antibodies, a subpopulation was unreactive, suggesting the existence of other types of mucin molecules.

To evaluate the similarity between airway and intestinal mucin at the mRNA level, we performed Northern blots and compared SMUC 41 hybridization signals in RNA from airways and intestine. RNA was extracted from tumor-free colon and bronchus specimens removed during tumor surgery from two individuals. The bronchus tissue was from a smoker with chronic bronchitis. Hybridization of bronchus poly (A) ${ }^{+}$RNA with the human small intestinal mucin cDNA SMUC 41 was first performed under low-stringency washing conditions $(2 \times$ $\mathrm{SSC}, 50^{\circ} \mathrm{C}$ ). The signal persisted, however, under high-stringency washing conditions $\left(0.2 \times \mathrm{SSC}, 63^{\circ} \mathrm{C}\right)$, indicating a high degree of homology between human intestinal and airway mucin mRNAs. The airway mucin mRNA showed a polydisperse hybridization signal similar to that in the intestine (Fig. 2, also see reference 12). That RNA degradation did not account for the observed polydispersity was indicated by the fact that the RNA showed sharp ribosomal bands on ethidium bromide stained agarose gels. This was supported by reprobing the same blots with a beta-actin probe, which revealed sharp bands of the expected size (Fig. 2). Based on accumulating data from several laboratories $(12,30)$, polydispersity is considered an inherent property of mucin mRNA.

To further investigate the degree of homology between intestinal and airway mucin, we used the intestinal mucin probe SMUC 41 to isolate a cDNA encoding airway mucin. We constructed an airway library consisting of 350,000 independent recombinants before amplification. Screening of 30,000 plaque-forming units (pfu) of the unamplified library under highly stringent conditions with SMUC 41 yielded one strongly positive signal. After rescreening to clonality and in vivo excision of pBluescript vector, sequencing was performed on both strands. The sequence of the bronchus cDNA fragment HAM1 is highly homologous to the first repeat of the intestinal mucin cDNA SMUC 41 (Fig. $3 \mathrm{~A}$ ). The deduced amino acid sequence differs in four amino acids, but contains a copy of the highly conserved sequence TTTTVTPTPTPT characteristic of the three intestinal mucin cDNAs previously described (12) (Fig. $3 \mathrm{~B}$ ). The four amino acid substitutions were confirmed by bidirectional sequencing of an identical insert in a different clone. We interpret this substituted sequence to represent a repeat not contained in SMUC 40-41, but present on the same transcript.

As expected, hybridization of the intestinal mucin cDNA SMUC 41 and the bronchus CDNA HAM-1 to restriction fragments (Apa I and Hind III) of human genomic DNA yielded identical bands at 13.0 (Apa I) and $9.0 \mathrm{~kb}$ (Hind III) (Fig. 4). Based on this data, it is likely that a single gene encodes a mucin core protein in the airways and the intestine.

To investigate whether the same gene is expressed in other human mucin-producing tissues, we performed Northern analysis using poly (A) ${ }^{+}$RNA from surgical or autopsy specimens of mammary gland, cervix, and prostate. RNA from gall bladder was not poly $(\mathrm{A})^{+}$selected.

RNA blots hybridized with SMUC 41 showed polydisperse hybridization signals in the cervix, mammary gland, and gall bladder. Duplicate tissue samples for the above showed the 

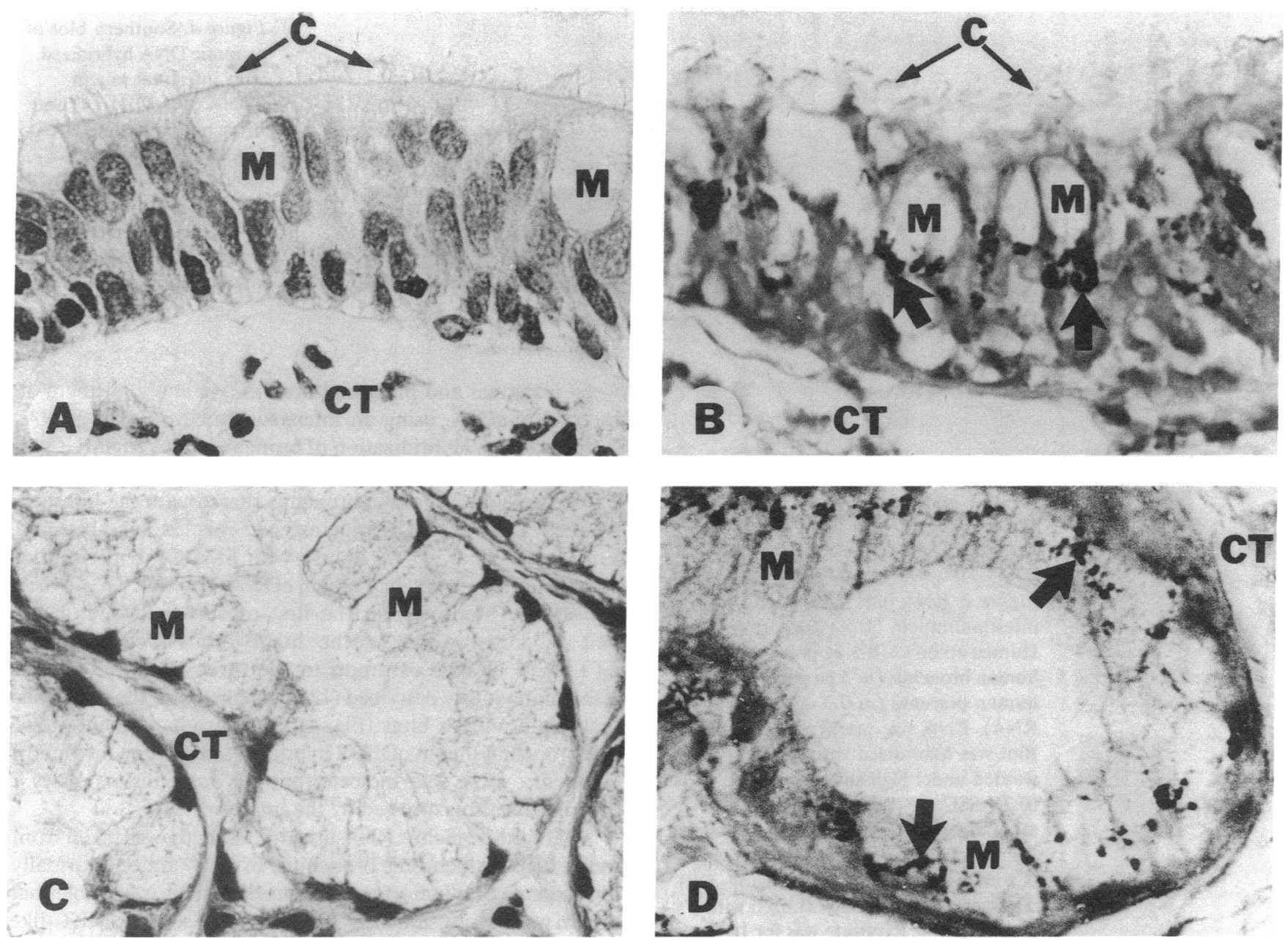

Figure 1. Immunocytochemical staining of human bronchus with intestinal mucin antibodies. $(A)$ Bronchial surface epithelium stained with hematoxylin and eosin. Magnification, 80. (B) Same as in $A$, but showing subcellular sites (arrows) containing antigen recognized by HFB (totally deglycosylated mucin peptide) antibody. Staining is below and around secretory granules, in the Golgi region of mucous cells. $(C)$ Bronchial mucous glands stained with hematoxylin and eosin. Magnification, 80. (D) Same as in $C$, but showing subcellular sites (arrows) containing antigen recognized by HFA (partially deglycosylated mucin peptide) antibody. Staining is below and around secretory granules, in the Golgi region of the mucous gland cells. $C$, cilia; $M$, mucous granules of mucous and goblet cells; $C T$, connective tissue.

same positive responses. RNA from prostate, however, showed a strong positive signal in only one of the two samples. This may have occurred due to differences in the regions taken for the biopsies, ages of the individuals, or clinical profiles. Rehybridization of all RNA samples with an actin cDNA showed sharp bands indicating that degradation of RNA could not account for the polydispersity observed in the mucin signals. The maximum size of the polydisperse signals varied among organs (Fig. 5). Comparing the actin and mucin signals within and between lanes, it is apparent that the various organs differ in the abundance of mucin message. This is not surprising in view of the differences in the number of mucous (goblet) cells and proportional volume of epithelium with respect to other tissue types within the various organs. That all of these signals survived high stringency washing conditions $\left(0.2 \times \mathrm{SSC}, 63^{\circ} \mathrm{C}\right)$ suggested that, like the airway mucin message, they are transcripts from the same or closely related mucin genes. This possibility remains to be tested by the isolation and analysis of cDNAs from these organs.

\section{Discussion}

The amino acid compositions of bronchial and intestinal mucins $(2,7,8)$ are similar enough to suggest that the mucins are built on similar or identical core proteins. Support for this view was obtained by Perini et al. (13) who demonstrated that material in the endoplasmic reticulum and Golgi region of intestinal mucous cells was recognized by an antiserum directed against deglycosylated bronchial mucins. In the present study, we have extended these results by showing that antibodies directed against deglycosylated intestinal mucins $(12,22,28)$ also recognize material in the endoplasmic reticulum and Golgi region of bronchial mucous cells. Thus, there is a reciprocal immunological cross-reactivity between mucins of the intestine and the bronchus.

The polyclonal antisera used by Perini et al. and ourselves likely contain antibodies directed against many different antigenic determinants, possibly corresponding to multiple mucin gene products. To better define the basis for the similarity be- 


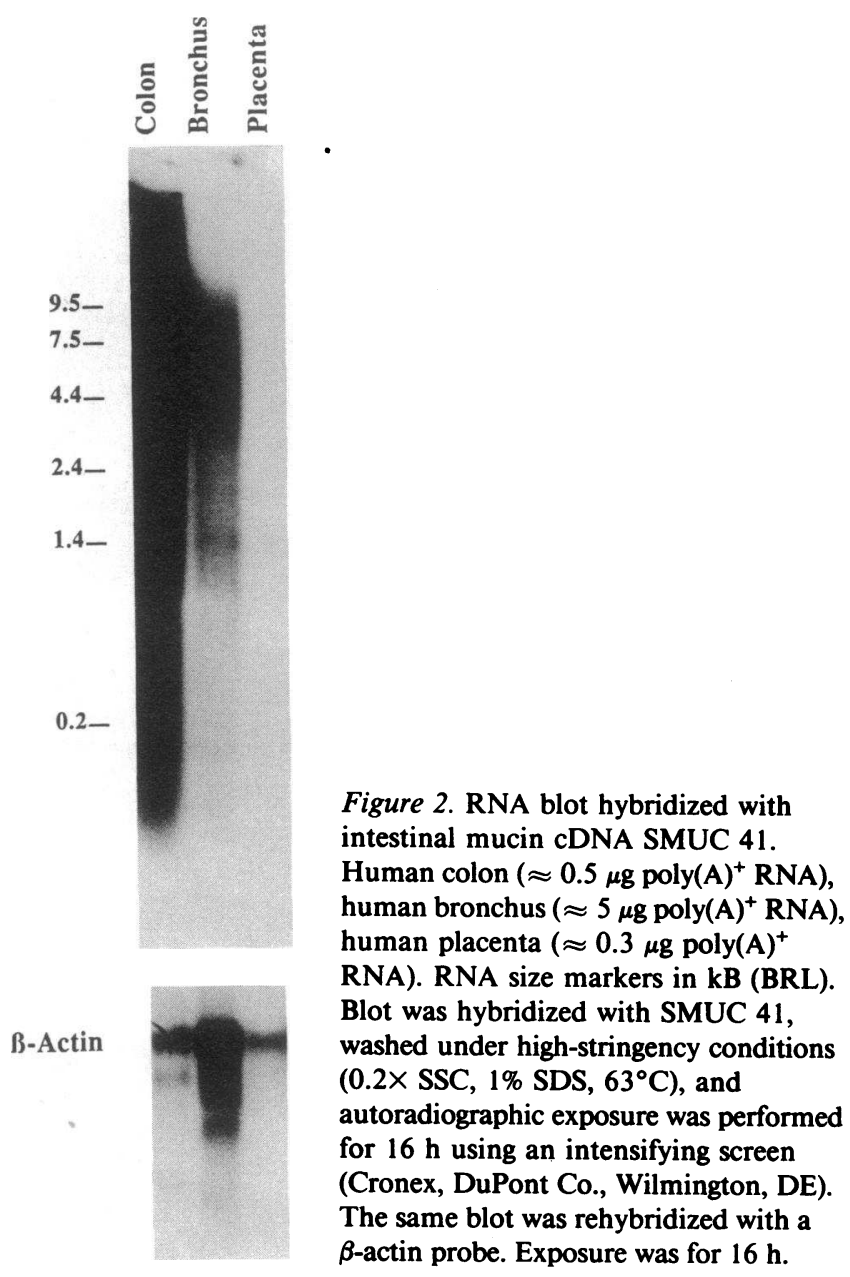

a

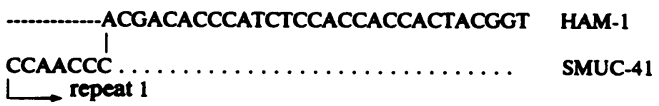

GACCCCAACCCCAACACCCACCGGCACACAGACC HAM-1

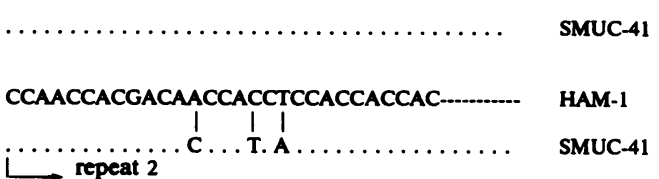

\section{TTPISTTUTVTPTPTPTGTQT PTTTTTSTIT} $\longrightarrow$ repeat 2

Figure 3. Nucleotide and deduced amino acid sequence comparison between bronchial mucin cDNA HAM-1 and intestinal mucin cDNA SMUC 41. $(A)$ Nucleotide sequence comparison, differences are indicated. $(B)$ Amino acid sequence of HAM-1. The highly conserved sequence described by Gum et al. (12) is underlined.
Figure 4. Southern blot of genomic DNA hybridized with intestinal mucin cDNA SMUC $41(A)$ and bronchial mucin cDNA HAM-1 (B). Blot was hybridized with SMUC 41, stripped, and reprobed with HAM-1 as described under Methods. DNA size markers in $\mathbf{k B}(\mathrm{BRL})$. tween intestinal and bronchial mucins, we analyzed them at the level of RNA, using an intestinal mucin-specific cDNA, SMUC 41 (12). Hybridization of bronchial RNA to SMUC-41 survived high-stringency washing conditions (Fig. 2), supporting the possibility that the bronchus shared with the intestine expression of the SMUC mucin gene. This led us to screen a human bronchial cDNA library with SMUC-41, permitting the isolation of a bronchial mucin cDNA, HAM-1. This cDNA shows $96 \%$ homology to the first repeat of SMUC 41 as well as conservation of the highly conserved sequence TTTTVTPTPTPT common to the three intestinal mucin cDNAs previously described (12). Together with the data from genomic Southern blots (Fig. 4), showing that the intestinal and bronchial mucin cDNAs hybridize to the same restriction fragments, these data indicate that the bronchus expresses a mucin gene also expressed by the intestine.

All of the bronchus RNA used in this study was taken from individuals with chronic bronchitis. In view of the abnormally high mucus production seen in this disease, it is possible that mucin gene expression is itself abnormal. If so, the SMUC-like transcripts we observed by both Northern blot and library screening may be peculiar to diseased airways. Because it is difficult to obtain RNA from healthy human airways, the question of whether SMUC or other mucin genes are expressed in the absence of disease must remain open at this time.

Recent evidence (29) has shown that antibodies directed against intestinal mucin (LS, HFA, HFB) cross-react with mucin-producing organs deriving embryologically from endoderm (bronchus and intestine), but not ectoderm (urogenital tract) or mesoderm (mammary gland). Extending the analysis to the RNA level in the present study, we obtained SMUC 41 hybridization signals, under high stringency washing conditions, from gall bladder (endodermal), cervix (ectodermal), and mammary gland (mesodermal). This indicates that expression of the SMUC-41 cognate gene is widespread throughout the mucin-producing organs of the human body. RNA processing or posttranscriptional modifications of the core protein may account for the differences observed between our hybridization data and the immunocytochemical data reported by Yan et al. (29).

The total number of human mucin genes and their possible coexpression by various organs is currently unknown. The present study provides the first evidence for coexpression of a single mucin gene in at least two separate organs (intestine and bronchus). It is likely from immunocytochemical studies that the PUM mucin gene is also expressed in two different organs (mammary gland and lung 30,31). Much remains to be learned about the nature of organ-specific processing of these co-expressed genes, at the level of both RNA and peptide. 


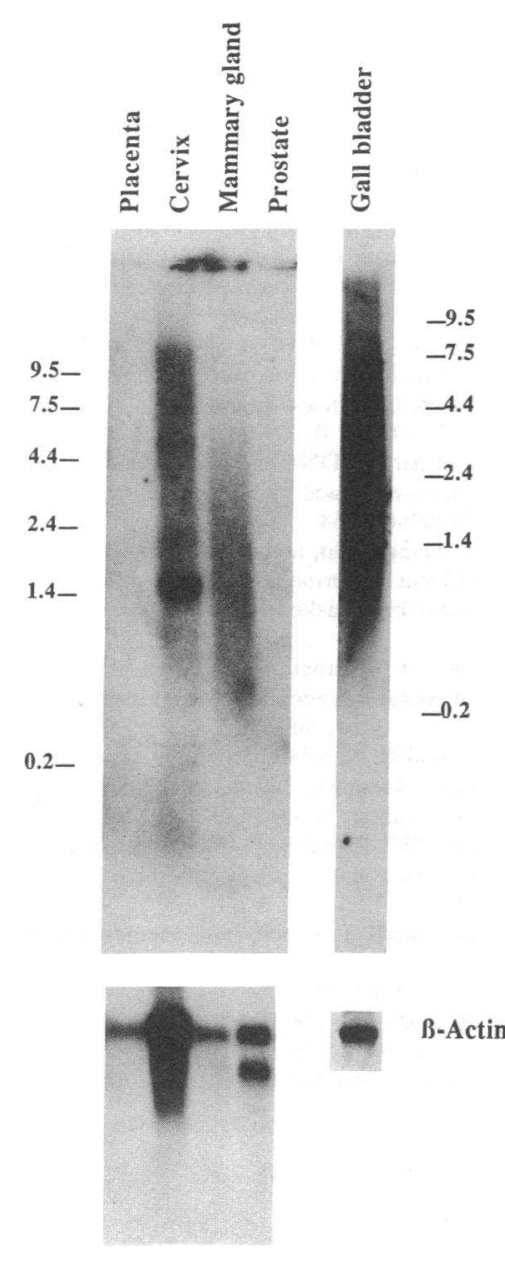

Figure 5. RNA blot of mucin-producing tissues hybridized with SMUC 41. Placenta $(\approx 0.3 \mu \mathrm{g}$ poly(A) ${ }^{+}$RNA), cervix $\left(\approx 6 \mu \mathrm{g}\right.$ poly $(\mathrm{A})^{+}$ RNA), mammary gland $\left(\approx 0.3 \mu \mathrm{g} \operatorname{poly}(\mathrm{A})^{+}\right.$ RNA $)$, prostate $(\approx 0.6$ $\mu \mathrm{g}$ poly $\left.(\mathrm{A})^{+} \mathrm{RNA}\right)$, gall bladder $(\approx 10 \mu \mathrm{g}$ total RNA). The gall bladder sample was run as part of a separate blot. Blots were hybridized with SMUC 41 and washed under identical highstringency conditions (0.2 $\times$ SSC, $1 \%$ SDS, $63^{\circ} \mathrm{C}$ ). Autoradiography was performed using an intensifying screen (Cronex, Dupont). Exposure was for $72 \mathrm{~h}$. Blots were stripped and rehybridized with a $\beta$ actin probe. Exposure was for $16 h$.

The present data on the expression of the SMUC gene in the human bronchus is the fourth example of a mucin-secreting organ producing mucin with the property of tandem repeats. Other examples are the mammary gland tumor mucin (11), the human SMUC intestinal mucin (12), and the porcine submandibular gland mucin (32). The repeat structure apparently represents a modular glycosylation unit. Each threonine-rich peptide repeat should present similar or identical glycosylation sites for cellular glycosyltransferases. The presence of tandem repeats means that despite considerable heterogeneity, there may exist ordered domains of specific oligosaccharide chains repeating $n$ times. The modular nature of the mucin monomer should lend itself to length modification by alternative splicing, a phenomenon which could account for the remarkable polydispersity of mucin message length (this paper, 12, 30).

Alternative splicing could be achieved by retained introns, the presence of alternate $5^{\prime}$ donor and $3^{\prime}$ acceptor sites, the use of alternative promotors and polyadenylation sites, internal mutually exclusive exons or cassette exons (for review 33 ). Consistent with this possibility is the observed polydispersity in (a) the length of bronchial glycoproteins $(8),(b)$ the molecular weight of mucin precursors (34), and (c) the molecular weight of deglycosylated mucin peptides (13).

Heterogeneous subpopulations of epithelial goblet or mucous gland cells may contribute to the observed polydispersity, since biochemically distinct subpopulations of mucous cells have been identified in both the intestine (35) and airways (36). Whatever the mechanism, the ability of a cell to modulate the length of the mucin monomer should enable it to influence mucus gel stability (resistance to dispersion) because the latter parameter is proportional to the square of the average monomer length (37).

Mucus hypersecretion is a key symptom of chronic bronchitis (15) and is correlated with the subsequent development of lung cancer $(17,21)$. The pathogenesis of hypersecretion has been difficult to understand due to the lack of biochemical markers. The availability of mucin cDNAs will facilitate studies of hypersecretion by providing tools with which to monitor steady-state levels of mucin mRNA in various pathological samples. Ultimately, analysis of the regulatory regions of mucin genes should reveal how mucin production is controlled at the first biosynthetic control point, that of mRNA transcription.

\section{Acknowledgments}

We thank Walter Finkbeiner, M. D., and Homer Boushey, M.D., for help in obtaining human specimens, and Charles Ordahl, Ph.D., for helpful discussions throughout this work. We also acknowledge the excellent photographic assistance of Manuel Uy.

Dr. Jany was partly supported by grants from the Deutsche Forschungsgemeinschaft (DFG), Boehringer Ingelheim, Inc., and Cystic Fibrosis Research, Inc. The research was partly supported by awards from the University of California San Francisco Academic Senate and NIH-PPG HL24136.

\section{References}

1. Basbaum, C. B., and W. E. Finkbeiner. 1989. Mucus-producing cells of the airways. In Lung Cell Biology. D. Massaro, editor. Marcel Dekker, New York 37-79.

2. Neutra, M. R., and J. F. Forstner. 1987. Gastrointestinal mucus: synthesis, secretion, and function. In Physiology of the Gastrointestinal Tract. L. R. Johnson, editor. Raven Press, New York. 975-1009.

3. Chantler, E. 1982. Structure and function of cervical mucus. In Mucus in Health and Disease. II. E. N. Chantler, J. B. Elder, and M. Elstein, editors. Plenum Publishing Corp., New York. 251-263.

4. Kornfeld, R., and S. Kornfeld. 1980. Structure of glycoproteins and their oligosaccharide units. In The Biochemistry of Glycoproteins and Proteoglycans. W. J. Lennarz, editor. Plenum Publishing Corp., New York. 1-34.

5. Caristedt, I., H. Lindgren, J. K. Sheehan, U. Ulmsten, and L. Wingerup. 1983. Isolation and characterization of human cervical-mucus glycoproteins. Biochem. J. 211:13-22.

6. Woodward, H., B. Horsey, V. P. Bhavanandan, and E. A. Davidson. 1982. Isolation, purification, and properties of respiratory mucus glycoproteins. Biochemistry. 21:694-701.

7. Woodward, H. D., N. J. Ringler, R. Selvakumar, I. M. Simet, V. P. Bhavanandan, and E. A. Davidson. 1987. Deglycosylation studies on tracheal mucin glycoproteins. Biochemistry. 26:5315-5322.

8. Slayter, H. S., G. Lamblin, A. Le Treut, C. Galabert, N. Houdret, P. Degand, and P. Roussel. 1984. Complex structure of human bronchial mucus glycoprotein. Eur. J. Biochem. 142:209-218.

9. Chace, K. V., M. Flux, and G. P. Sachdev. 1985. Comparison of physicochemical properties of purified mucus glycoproteins isolated from respiratory secretions of cystic fibrosis and asthmatic patients. Biochemistry. 24:7334-7341.

10. Gilks, C. B., P. E. Reid, P. B. Clement, and D. A. Owen. 1989. Histochemical changes in cervical mucus-secreting epithelium during the normal menstrual cycle. Fertil. Steril. 51:286-291.

11. Gendler, S., J. Taylor-Papadimitriou, T. Duhig, J. Rothbard, and J. Burchell. 1988. A highly immunogenic region of a human polymorphic epithelial mucin expressed by carcinomas is made up of tandem repeats. J. Biol. Chem. 263:12820-12823.

12. Gum, J. R., J. C. Byrd, J. W. Hicks, N. W. Toribara, D. T. A. Lamport, and Y. S. Kim. 1989. Molecular cloning of human intestinal mucin cDNAs. J. Biol. Chem. 264:6480-6487.

13. Perini, J.-M., T Marianne, J.-J. Lafitte, G. Lamblin, P. Roussel, and M. Mazzuca. 1989. Use of an antiserum against deglycosylated human mucins for cellular localization of their peptide precursors: antigenic similarities between bronchial and intestinal mucins. J. Histochem. Cytochem. 37:869-875. 
14. Boat, T. F., and D. G. Dearborn. 1984. Etiology and pathogenesis. In Cystic Fibrosis. L. M. Taussig, editor. Thieme, Stratton, New York. 25-84.

15. American Thoracic Society. 1962. Chronic bronchitis, asthma, and pulmonary emphysema: a statement by the Committee on Diagnostic Standards for Nontuberculous Respiratory Diseases. Am. Rev. Respir. Dis. 85:762-768.

16. Aikawa, T., S. Shimura, H. Sasaki, T. Takishima, H. Yaegashi, and T. Takahashi. 1989. Morphometric analysis of intraluminal mucus in airways in chronic obstructive pulmonary disease. Am. Rev. Respir. Dis. 140:477-482.

17. Peto, R., F. E. Speizer, A. L. Cochrane, F. Moore, C. M. Fletcher, C. M. Tinker, I. T. T. Higgins, R. G. Gray, S. M. Richards, J. Gilliland, and B. NormanSmith. 1983. The relevance in adults of air-flow obstruction, but not of mucus hypersecretion, to mortality from chronic lung disease. Am. Rev. Respir. Dis. 128:491-500.

18. Trump, F. B., E. M. McDowell, F. Glavin, L. A. Barret, P. J. Becci, W. Schurch, H. E. Kaiser, and C. C. Harris. 1978. The respiratory epithelium. III Histogenesis of epidermoid metaplasia and carcinoma in situ in the human. $J$. Natl. Cancer Inst. 61:563-575.

19. Pettijohn, D. E., P. L. Stranahan, C. Due, E. Ronne, H. R. Sorensen, and L. Olsson. 1987. Glycoproteins distinguishing non-small cell from small cell human lung carcinoma recognized by monoclonal antibody 43-9F. Cancer Res. 47:1161-1169.

20. Gould, V. E., S. S. Shin, G. L. Manderino, J. G. Tomita, and G. T. Gooch. 1988. Selective expression of novel mucin-type glycoprotein in human tumors: immunohistochemical demonstration with Mab A-80. Hum. Pathol. 19:623627.

21. Lange, P., J. Nyboe, M. Appleyard, G. Jensen, and P. Schnohr. 1990. Ventilatory function and chronic mucus hypersecretion as predictors of death from lung cancer. Am. Rev. Respir. Dis. 141:613-617.

22. Byrd, J. C., J. Nardelli, B. Siddiqui, and Y. S. Kim. 1988. Isolation and characterization of colon cancer mucin from xenografts of LS174T cells. Cancer Res. 48:6678-6685.

23. Chomczynski, P., and N. Sacchi. 1987. Single-step method of RNA isolation by acid guanidinium thiocyanate-phenol-chloroform extraction. Anal. Biochem. 162:156-159.

24. Sambrock, J., E. F. Fritsch, and T. Maniatis. 1982. Molecular Cloning. A Laboratory Manual. Cold Spring Harbor Laboratory Press, Cold Spring Harbor, NY.
25. Benton, W. D., and R. W. Davis. 1977. Screening lambda gt recombinant clones by hybridization to single plaques in situ. Science (Wash. DC). 196:180 182.

26. Short, J. M., J. M. Fernandez, J. A. Sorge, and W. D. Huse. 1988. Lambda ZAP: a bacteriophage lambda expression vector with in-vivo excision properties. Nucleic Acid Res. 16:7583-7600.

27. Sanger, F., S. Nicklen, and A. R. Coulson. 1977. DNA sequencing with chain terminating inhibitors. Proc. Natl. Acad. Sci. USA. 74:5463-5467.

28. Kuan, S. F., J. C. Byrd, C. B. Basbaum, and Y. S. Kim. 1987. Characterization of quantitative mucin variants from a human colon cancer cell line. Cancer Res. 47:5715-5724.

29. Yan, P.-S., S. B. Ho, S. H. Itzkowitz, J. C. Byrd, B. Siddiqui, and Y. S. Kim. 1990. Expression of native and deglycosylated colon cancer mucin antigens in normal and malignant epithelial tissues. Lab. Invest. In press.

30. Gendler, S. J., J. M. Burchell, T. Duhig, R. White, M. Parker, and J. Taylor-Papadimitriou. 1987. Cloning of partial cDNA encoding differentiation and tumor-associated mucin glycoproteins expressed by human mammary epithelium. Proc. Natl. Acad. Sci. USA. 84:6060-6064.

31. Griffiths, B., L. G. Bobrow, L. Happerfield, and D. M. Swallow. 1988. Expression of the hypervariable PUM locus in normal and malignant lung: the tumour-associated epitopes are present but masked in normal tissue. Dis. Markers. 6:195-202.

32. Timpte, C. S., A. E. Eckhardt, J. L. Abernethy, and R. L. Hill. 1988. Porcine submaxillary gland apomucin contains tandemly repeated identical sequences of 81 residues. J. Biol. Chem. 263:1081-1088.

33. Smith, C. W. J., J. G. Patton, and B. Nadal-Ginard. 1989. Alternative splicing in the control of gene expression. Annu. Rev. Genet. 23:527-577.

34. Marianne, T., J.-M. Perini, J.-J. Lafitte, N. Houdret, F.-R. Pruvot, G. Lamblin, H. S. Slayter, and P. Roussel. 1987. Peptides of human bronchial mucus glycoproteins: size determination by electron microscopy and by biosynthetic experiments. Biochem. J. 248:189-195.

35. Podolsky, D. K., D. A. Fournier, and K. E. Lynch. 1986. Human colonic goblet cells: demonstration of distinct subpopulations defined by mucin-specific monoclonal antibodies. J. Clin. Invest. 77:1263-1271.

36. Finkbeiner, W. E., and C. B. Basbaum. 1988. Monoclonal antibodies directed against human airway secretions. Am. J. Pathol. 131:290-297.

37. Verdugo, P. 1990. Goblet cells secretion and mucogenesis. Annu. Rev. Physiol. 52:157-176. 